\title{
Morbidity and mortality patterns of post- neonatal paediatric medical admissions in a large mission hospital in Benin City, Nigeria
}

\author{
AN Onyiriuka
}

\begin{abstract}
This study was conducted to determine the morbidity and mortality pattern in children admitted into a mission hospital and to compare the results with those obtained from public hospitals. It was a retrospective study that reviewed the admission and outpatient attendance registers as well as the case records of all children aged between one month and 14 years admitted into St. Philomena Catholic Hospital (SPCH), Benin City, from 1st January 2000 to 31st December 2001. Out of the 8172 children seen at the paediatric outpatient clinic, 1210 (14.8\%) were admitted; comprising of 646 (53.4\%) males and 564 (46.6\%) females. Under-fives accounted for $84.0 \%$ of these admissions. Slightly more cases were admitted during the wet season 632 (52.3\%) than the dry season 578 (47.7\%). Malaria and its complications (61.1\%), gastroenteritis (16.6\%) and acute lower respiratory tract infection (ALRTI) $(8.7 \%)$ were the three commonest causes of childhood hospitalisation. Other causes include anaemia (3.7\%), measles (3.6\%) and febrile convulsion (3.3\%). Overall, mortality rate was $4.1 \%$, with under-fives accounting for $92.0 \%$ of these deaths. Mortality rate in under-fives was $18.0 \%$, while mortality rate was 1.7 times higher in girls than boys. The commonest causes of death were malaria and its complications (52.0\%), anaemia (18.0\%), gastroenteritis $(14.0 \%)$, measles (8.0\%) and ALRTI (6.0\%). High case fatality rates were found in cerebral malaria (27.8\%), anaemia (20.0\%), meningitis (20.0\%) and measles (9.1\%). The commonest cause of death among infants (excluding neonates) was gastroenteritis, while malaria-induced anaemia was the commonest cause of death among children aged 1-4 years. Malaria and its complications, gastroenteritis, ALRTI and severe anaemia are the most important causes of childhood morbidity and mortality in Benin City. Health interventions aimed at controlling these diseases should be strengthened if childhood morbidity and mortality are to be significantly reduced. Greater resources should be allocated to the health care needs of under-fives especially during the wet season.
\end{abstract}

\section{INTRODUCTION}

Hospital admission data can be a valuable tool for assessing the epidemiology of diseases

KEY WORDS: Childhood, morbidity, malaria, ALRTI, gastroenteritis, Nigeria

Department of Child Health, College of Medical Sciences, University of Benin, Benin City, Nigeria.

(C) CMS UNIBEN JMBR 2005; 4(1): 49-58 within populations. With minimum data collection, substantial insight can be had into the types of diseases, the age at which conditions present and their burden on inpatient service. There are few reports on childhood morbidity and mortality from private health institutions. Majority of the health statistics on pattern of childhood morbidity and mortality in Nigeria are derived 
from data obtained from the nation's teaching hospitals. Previous reports from these teaching hospitals indicate that acute lower respiratory tract infections (ALRTI), gastroenteritis and anaemia were the most common medical causes of childhood hospital admissions. ${ }^{1-4}$ A similar finding has also been reported in a previous study in a private hospital in Enugu. ${ }^{5}$ This is in contrast to the report of a recent study in a private hospital in Lagos, which showed that malaria was the commonest cause of childhood hospitalisation. ${ }^{6}$

Knowledge of the morbidity profile enables policymakers, health care planners and managers to reach informed decisions on allocation of human and material resources to the various areas within the health subsector. Also, an estimate of disease-specific burden is required for setting national priorities for health. Sources of data for such an estimate must include both public and private health institutions in Nigeria. Using data from public health institutions only may not depict the true childhood morbidity and mortality patterns for the nation.

In recent years, in Nigeria, there has been tremendous increase in the number of private health facilities that provide health care services for children. Thus, they contribute significantly to the provision of health care to the populace. Therefore, data from private health institutions are required to give a balanced picture of childhood morbidity and mortality pattern in Nigeria. This study sought to determine the morbidity and mortality pattern amongst children admitted into a mission hospital and compare the results with those obtained from public hospitals.

\section{PATIENTS AND METHODS}

This retrospective study was conducted at St. Philomena Catholic Hospital (SPCH), Benin City. SPCH is a mission hospital established 62 years ago and is located in the centre of Benin City, the Edo State capital. Its paediatric section consists of a special care baby unit
(SCBU) with eight cots and three functioning incubators, and a children's ward with 24 beds and two semi-private rooms each with two beds. The hospital has a fairly equipped laboratory capable of performing routine laboratory investigations such as blood smears for malaria parasites, full blood count, urinalysis and urine culture. Other investigations performed include genotype, serum urea and electrolytes, bilirubin, protein, alkaline phosphatase, blood grouping and cross-matching. It also has a good blood bank facility. Other hospitals in Benin City (both public and private) also make use of SPCH's laboratory and blood bank facilities. The laboratory and blood bank have 24-hour coverage by six trained full-time medical laboratory scientists.

The paediatric section enjoys 24-hour coverage by a consultant paediatrician, resident doctors (senior registrars) from the University of Benin Teaching Hospital (UBTH), four senior medical officers and two medical officers (with five-year and three-year post-qualification experience respectively). The nursing personnel consist of a trained paediatric nurse and 10 trained staff nursemidwives. The hospital patients consist of private fee-paying patients and staff/ dependants of private companies, which have retained the services of the hospital. The patients therefore represent various strata of the society cutting across social classes, religions and ethnic groups. The place of residence of majority of the patients extended from the immediate location of the hospital to a distance as far as $50 \mathrm{~km}$ approximately.

The admission registers and case notes of all children aged one month to 14 years admitted into the hospital from 1st January 2000 to 31st December 2001 were examined and the relevant information extracted. The case notes were well kept and easy to retrieve from the records section. Information obtained from the case notes and registers include date of admission, ethnic group, place of residence, 
age, sex and main diagnosis. The outcome of hospitalisation such as deaths and discharges were noted for each patient. The principal reason for admission of the child was accepted as the main diagnosis, which was determined by the consultant paediatrician. The paediatric outpatient clinic attendance registers were examined to obtain data on total number of children seen at the hospital for the two-year period. The data obtained were analysed and the results compared with those of previous studies from the teaching hospitals in Nigeria. Permission to conduct this study was sought and obtained from the chief medical officer of the hospital.

In this study, the seasons were defined as the wet season (May to October) and the dry season (November to April) in accordance with the well-known characteristics of the climate of Nigeria., ${ }^{7,8}$
Statistical analysis involved calculation of percentages, ratios, averages and confidence intervals. The Z-test and chi square test were used in ascertaining the level of significance of differences, which was set at $\mathrm{p}<0.05$.

\section{RESULTS}

\section{Overall admission rate}

During the two-year period, a total of 8,172 children (aged one month to 14 years) were seen at the outpatient clinic of the hospital. Of this number, 1,210 (14.8\%) were admitted into the children's ward. The average in-patient census was 50 patients, corresponding to a bed occupancy rate of $179.0 \%$

\section{Sex and age group of children admitted}

Among the 1,210 children who were admitted, 646 (53.4\%) were males while 564 (46.6\%)

\section{Table $1 \quad$ Age and sex distribution of children admitted}

\begin{tabular}{llccr}
\hline $\begin{array}{l}\text { Age group } \\
\text { (years) }\end{array}$ & \multicolumn{1}{c}{ Sex } & Female (\%) & Total (\%) & Z-statistic (p value) \\
\hline$<1$ & $194(53.6)$ & $168(46.4)$ & $362(29.9 \%)$ & $1.370(>0.05)$ \\
$1-4$ & $353(53.9)$ & $302(46.1)$ & $655(54.1)$ & $1.996(<0.05)$ \\
$5-14$ & $101(52.3)$ & $92(47.7)$ & $193(16.0)$ & $0.639(>0.05)$ \\
\hline Total (\%) & $646(53.4)$ & $564(46.6)$ & $1210(100.0)$ & $2.365(<0.05)$ \\
\hline
\end{tabular}

Table 2 Main diagnosis in the study population

\begin{tabular}{lrr}
\hline $\begin{array}{l}\text { Main diagnosis in hospitalised } \\
\text { children }\end{array}$ & $\begin{array}{r}\text { No. of children } \\
\text { admitted }\end{array}$ & $\begin{array}{r}\text { Percentage of total } \\
\text { admitted }\end{array}$ \\
\hline Malaria (uncomplicated) & 541 & 44.7 \\
Malaria with severe anaemia & 180 & 14.9 \\
Cerebral malaria & 18 & 1.5 \\
Gastroenteritis & 201 & 16.6 \\
ALRTI & 105 & 8.7 \\
Anaemia (excluding SCA) & 45 & 3.7 \\
Measles & 44 & 3.6 \\
Febrile convulsion & 40 & 3.3 \\
Sickle cell anaemia (SCA) & 13 & 1.1 \\
Acute severe asthma & 7 & 0.6 \\
Acute poisoning & 7 & 0.6 \\
Meningitis & 5 & 0.4 \\
Epilepsy & 4 & 0.3 \\
\hline Total & 210 & 100
\end{tabular}

ALRTI = Acute lower respiratory tract infection 
were females (Z-statistic $=2.365 \mathrm{p}<0.05$ ). Male to female ratio was $1.2: 1$, while the average patient age was 5.1 years $(95 \%$ CI $=4.8-$ 5.3). Eighty four per cent of the children were less than five years old and 29.9\% were aged less than one year. Of the 201 patients with gastroenteritis, 109 (54.2\%) were less than one year old.

\section{Re-admission rate}

A total of 43 (3.6\%) children were admitted twice while $11(0.9 \%)$ children were admitted three times; representing a re-admission rate of $4.5 \%$.

\section{Ethnic origin}

The various ethnic groups represented among the hospitalised children were: Bini (47.8\%),

\section{Table 3 Seasonal distribution of main diagnosis}

\begin{tabular}{lrrrc}
\hline $\begin{array}{l}\text { Main diagnosis in } \\
\text { hospitalised children }\end{array}$ & Wet season & Dry season & Total & Z-statistic (p value) \\
\hline Malaria (uncomplicated) & $296(54.7)$ & $245(45.3)$ & 541 & $2.186(<0.05)$ \\
Malaria with severe anaemia & $105(58.3)$ & $75(41.7)$ & 180 & $2.227(<0.05)$ \\
Cerebral malaria & $11(61.1)$ & $7(38.9)$ & 18 & $0.942(>0.05)$ \\
Gastroenteritis & $177(88.1)$ & $24(11.9)$ & 201 & $10.819(<0.001)$ \\
ALRTI & $47(44.8)$ & $58(55.2)$ & 105 & $1.066(>0.05)$ \\
Anaemia (excluding SCA) & $33(73.3)$ & $12(26.7)$ & 45 & $3.125(<0.01)$ \\
Measles & $10(22.7)$ & $34(77.3)$ & 44 & $3.623(<0.001)$ \\
Febrile convulsion & $30(75.0)$ & $10(25.0)$ & 40 & $3.162(<0.01)$ \\
Sickle cell anaemia & $8(61.5)$ & $5(38.5)$ & 13 & $0.829(>0.05)$ \\
Acute severe asthma & $4(57.1)$ & $3(45.9)$ & 7 & $0.376(>0.05)$ \\
Acute poisoning & $3(42.8)$ & $4(57.2)$ & 7 & $0.376(>0.05)$ \\
Meningitis & $2(40.0)$ & $3(60.0)$ & 5 & $0.447(>0.05)$ \\
Epilepsy & $2(75.0)$ & $1(25.0)$ & 4 & $1.000(>0.05)$ \\
Total & $729(60.2)$ & $481(39.8)$ & 1210 & $7.095(<0.001)$ \\
\hline
\end{tabular}

Figures in parentheses are percentages

Table 4 Principal causes of childhood admissions in the present study compared to previous studies in Nigeria

\begin{tabular}{|c|c|c|c|c|c|}
\hline \multirow{2}{*}{$\begin{array}{l}\text { Main diagnosis in the study } \\
\text { population }(n=1210)\end{array}$} & \multicolumn{5}{|c|}{ Percentage from each study centre } \\
\hline & $\begin{array}{r}\text { Benin City } \\
\text { (current } \\
\text { study) }\end{array}$ & $\begin{array}{r}\text { Enugu }^{5} \\
(1976)\end{array}$ & $\begin{array}{r}\text { Benin } \\
\text { City }^{1} \\
(\mathbf{1 9 8 0})\end{array}$ & $\begin{array}{r}\text { Ilesha }^{9} \\
\text { (1996) }\end{array}$ & $\begin{array}{r}\text { Lagos }^{6} \\
(1998)\end{array}$ \\
\hline Malaria (uncomplicated) & 44.7 & - & 2.6 & 7.9 & 17.8 \\
\hline Malaria with severe anaemia & 14.9 & - & - & - & - \\
\hline Cerebral malaria & 1.5 & - & - & - & - \\
\hline Gastroenteritis & 16.6 & 22.5 & 27.0 & 14.4 & 16.8 \\
\hline ALRTI & 8.7 & 15.0 & 29.6 & 15.2 & 13.8 \\
\hline Anaemia (excluding SCA) & 3.7 & - & 3.0 & 7.3 & 1.9 \\
\hline Measles & 3.6 & - & 17.0 & 5.3 & 5.2 \\
\hline Febrile convulsion & 3.3 & 20 & 5.0 & 8.4 & 5.1 \\
\hline Sickle cell anaemia & 1.1 & - & 2.7 & 2.6 & 1.9 \\
\hline Acute severe asthma & 0.6 & - & - & - & - \\
\hline Acute poisoning & 0.6 & 10.0 & - & - & - \\
\hline Meningitis & 0.4 & - & - & - & - \\
\hline Epilepsy & 0.3 & - & - & - & - \\
\hline
\end{tabular}


Igbo (20.6\%), Ishan (13.0\%), Urhobo/Isoko/ Ijaw (6.7\%), Etsako (5.2\%), Yoruba (4.1\%), non-Nigerians (1.9\%) and others (0.7\%). Analysis comparing mortality rates amongst the various ethnic groups did not show any difference.

\section{Season and rate of hospitalisation}

Out of the 1,210 children admitted, 632 (52.2\%) were admitted during the wet season, while the remaining 578 (47.8\%) were admitted during the dry season (Z-statistics $=1.530 \mathrm{p}>0.05)$.
Season and main diagnosis

Of all cases of gastroenteritis, febrile convulsions and severe anaemia, 88.1\%, 75.0\% and $73.3 \%$ respectively were admitted during the wet season while the corresponding morbidities admitted during the dry season were measles (77.3\%) and acute lower respiratory tract infection (55.2\%). Of the 739 cases of malaria and its complications admitted, 412 (55.8\%) were admitted during the wet season, while the remaining 327 (44.2\%) were admitted during the dry season (Z-statistics $=3.153 \mathrm{p}<0.01)$.

Table 5 Mortality by sex and by age

\begin{tabular}{lllllll}
\hline $\begin{array}{l}\text { Age group } \\
\text { (years) }\end{array}$ & \multicolumn{2}{c}{ Male } & \multicolumn{2}{c}{ Female } & \multicolumn{2}{c}{ Both sexes combined } \\
& $\begin{array}{l}\text { No. of } \\
\text { children } \\
\text { admitted }\end{array}$ & $\begin{array}{l}\text { No. of } \\
\text { deaths (\%) } \\
\text { admitted }\end{array}$ & $\begin{array}{l}\text { No. of } \\
\text { children } \\
\text { admitted }\end{array}$ & $\begin{array}{l}\text { No. of } \\
\text { deaths (\%) }\end{array}$ & $\begin{array}{l}\text { Total no. of } \\
\text { children }\end{array}$ & $\begin{array}{l}\text { Total no. of } \\
\text { deaths }\end{array}$ \\
& 194 & $7(3.6)$ & 168 & $11(6.5)$ & 362 & $18(5.0)$ \\
\hline$<1$ & 353 & $11(3.1)$ & 302 & $17(5.6)$ & 655 & $28(4.3)$ \\
$1-4$ & $2(0.0)$ & 92 & $2(2.2)$ & 193 & $4(2.1)$ \\
$5-14$ & 101 & $20(3.1)$ & 564 & $30(5.3)$ & 1210 & $50(4.1)$ \\
\hline Total & 646 & &
\end{tabular}

Figures in parentheses are percentages

Table $6 \quad$ Case fatality rates by main diagnosis

\begin{tabular}{lrrr}
\hline $\begin{array}{l}\text { Main diagnosis in the study } \\
\text { population }\end{array}$ & $\begin{array}{r}\text { No. of children } \\
\text { admitted }\end{array}$ & No. of deaths & \% Case fatality rate \\
\hline Malaria (uncomplicated) & 541 & 6 & 1.1 \\
Malaria with severe anaemia & 180 & 15 & 8.3 \\
Cerebral malaria & 18 & 5 & 27.8 \\
Gastroenteritis & 201 & 7 & 3.5 \\
ALRTI & 105 & 3 & 2.9 \\
Anaemia (excluding SCA) & 45 & 9 & 20.0 \\
Measles & 44 & 4 & 9.1 \\
Febrile convulsion & 40 & - & 0 \\
Sickle cell anaemia (SCA) & 13 & - & 0 \\
Acute severe asthma & 7 & - & 0 \\
Acute poisoning & 7 & 1 & 0 \\
Meningitis & 5 & - & 20.0 \\
Epilepsy & 4 & 50 & 0 \\
Total & 1210 & & 4.1 \\
\hline
\end{tabular}




\section{Sex, Mortality and Season}

Fifty (4.1\%) of the 1,210 children admitted died, consisting of $20(40.0 \%)$ males and 30 $(60.0 \%)$ females (Z-statistic $=3.162 \mathrm{p}<0.001)$. The death rate during the wet season was 26 (2.1\%), while it was $24(2.0 \%)$ during the dry season $\left(\chi^{2}=1.298 \mathrm{p}>0.05\right)$. Eleven $(42.3 \%)$ of the 26 deaths during the wet season were boys, while the remaining 15 (57.7\%) were girls (Z-statistic $=0.785 \mathrm{p}>0.05$ ). Twenty four children died during the dry season, consisting of 9 (37.5\%) boys and 15 (62.5\%) girls (Z- statistic $=1.225 \mathrm{p}>0.05)$.

Table 1 shows that under-fives and those aged 5-14 years accounted for $84.0 \%$ and $16.0 \%$ of all admissions respectively ( $\mathrm{Z}$ statistic $=29.728 \mathrm{p}<0.001)$. More boys than girls were admitted for all age groups, with a statistically significant difference obtained in the 1-4 years age group.

Table 2 shows that simple malaria as well as complicated malaria was the major cause of hospitalisation, accounting for $61.1 \%$ of total admissions. Other important causes of admission were gastroenteritis, acute lower respiratory tract infection (ALRTI) and anaemia.
The rate of admission was one and a half times higher in the wet season than in the dry season (Table 3). The major causes of hospitalisation during the wet season were malaria and its complications, gastroenteritis, anaemia and febrile convulsion. The major causes of hospitalization during the dry season were malaria and its complications, ALRTI and measles.

There was a remarkable increase in the proportion of cases admitted for malaria and its complications in the current study when compared to previous studies (Table 4). The proportion of cases admitted for gastroenteritis remained unchanged from 1996 to 2001. There was a marked decrease in the proportion of admissions due to ALRTI and measles.

Table 4 shows that $92.0 \%$ of deaths occurred in under-fives with an under-five mortality rate of $18.0 \%$. Overall mortality rate was $4.1 \%$, with $5.3 \%$ for girls and $3.1 \%$ for boys, which corresponds to $60.0 \%$ and $40.0 \%$ of total deaths respectively (Z-statistic $=1.414$ $\mathrm{p}>0.05)$. Male to female ratio was 1:1.5. Children aged less than one year accounted for $36.0 \%$ of all deaths while all the other age

\section{Table $7 \quad$ Age distribution of associated causes of deaths $(\mathbf{n}=\mathbf{5 0})$}

\begin{tabular}{llrl}
\hline Associated causes of death & \multicolumn{1}{c}{ Age group (years) } & $\mathbf{5 - 1 4}$ \\
\hline Malaria severe & $2(4.0)$ & $\mathbf{1 - 4}$ & $1(2.0)$ \\
Malaria with anaemia & $2(6.0)$ & $12(6.0)$ & $1(2.0)$ \\
Cerebral malaria & $3(6.0)$ & $2(4.0)$ & $0(0)$ \\
Gastroenteritis & $6(12.0)$ & $1(2.0)$ & $0(0)$ \\
ALRTI & $3(6.0)$ & $1(2.0)$ & $1(2.0)$ \\
Anaemia (excluding SCA) & $0(0)$ & $5(10.0)$ & $1(2.0)$ \\
Measles & $1(2.0)$ & $3(6.0)$ & $0(0)$ \\
Febrile convulsion & $0(0)$ & $0(0)$ & $0(0)$ \\
Sickle cell anaemia & $0(0)$ & $0(0)$ & $0(0)$ \\
Acute severe asthma & $0(0)$ & $0(0)$ & $0(0)$ \\
Acute poisoning & $0(0)$ & $0(0)$ & $0(0)$ \\
Meningitis & $1(2.0)$ & $0(0)$ & $0(0)$ \\
Epilepsy & $0(0)$ & $0(0)$ & $0(0)$ \\
Total & $19(38.0)$ & $27(54.0)$ & $4(8.0)$ \\
\hline
\end{tabular}

Figures in parentheses are percentages 
groups put together accounted for $64.0 \%$ of all deaths (Z-statistic $=9.291 \mathrm{p}<0.001)$.

The highest case-fatality rate was among children with cerebral malaria, followed by anaemia and meningitis (Table 6). Out of the 50 deaths, malaria and its complications accounted for $52.0 \%$, anaemia $18.0 \%$, gastroenteritis $14.0 \%$ and measles $8.0 \%$. The leading cause of death in infants less than one year old was gastroenteritis, while it was malaria with severe anaemia in the $1-4$ years age group (Table 7).

\section{DISCUSSION}

In consonance with previous reports, ${ }^{6,9,10}$ majority of the children (84.0\%) requiring hospitalisation in this study were less than five years old, further confirming the vulnerability of under-fives to various illnesses. This may be explained by the fact that at this period of life the passively acquired maternal immunity is already waning and the child is still developing his/ her own natural immunity. ${ }^{11}$ As a result, the child is susceptible to various infections such as malaria, acute respiratory infections and measles. Also, because of lack of safe water and poor sanitation in the homes as well as unhygienic handling of the infant's feeds he/ she suffers from recurrent episodes of diarrhoea. ${ }^{12,13}$

Significantly more boys than girls were admitted during the period covered by this review. Similar gender differentials in rates of hospitalisation have been reported in Lagos ${ }^{6}$ and Catalonia. ${ }^{14}$ There is no ready explanation for the male preponderance in hospital admissions. It is possible that parents have a higher tendency to accept hospital admissions for their ill sons than for their ill daughters. This is probably because of the cultural parental preference for male children. This would however require further research and would be the focus of another study.

The rate of hospitalisation was significantly higher during the wet season than the dry season, suggesting that there may be (C) CMS UNIBEN JMBR 2005; 4(1): 49-58 seasonal variations in childhood morbidities in our communities. This is similar to findings from Gambia. ${ }^{15}$ Comparison with previous studies was however not possible because the authors did not analyse their hospital admission rates according to season. Increased hospitalisation during the wet season may be explained by our finding that the major causes of admission such as malaria and its complications, gastroenteritis, anaemia and febrile convulsion occur more frequently during the wet season than during the dry season. The leading role of malaria as a cause of childhood hospitalisation and mortality in this study has also been documented by other investigators in Nigeria ${ }^{6}$ and other African countries such as Sierra Leone, ${ }^{16}$ Ethiopia $^{17}$ and Kenya. ${ }^{18}$ In contrast, malaria ranked very low as a cause of childhood hospital admissions in previous studies in the teaching hospitals in Benin, ${ }^{1}$ Ibadan, ${ }^{2}$ Ilorin, ${ }^{3}$ Port Harcourt ${ }^{4}$ and a private hospital in Enugu. ${ }^{5}$ A possible explanation is the changing pattern of malaria with increasing incidence of resistance to various anti-malarial drugs in recent years. ${ }^{19,20}$ This also explains the leading role of malaria as a cause of childhood mortality in this study.

Drug resistance may lead to treatment failures. Delay in recognising treatment failures may lead to death. These studies ${ }^{1-5}$ were conducted over 15 years ago. In view of the fact that malaria ranks first as a cause of childhood hospitalisation, any plan to reduce childhood morbidity rate in Nigeria (and perhaps other malaria endemic countries) must include early diagnosis, prompt and adequate treatment and prevention of malaria in children. Fortunately, the Roll Back Malaria programme and the use of insecticide treated bed nets currently being advocated are useful health interventions to curtail the escalating threat from malaria.

Two other principal causes of hospitalisation in this study and that of $\operatorname{Lagos}^{6}$ are gastroenteritis and ALRTI. Reports from other African countries also confirm the leading 
role of these preventable diseases as causes of childhood morbidity and mortality. ${ }^{16-18}$ This underlies the need to strengthen preventive paediatrics. On the other hand, there is a lower proportion of cases admitted for ALRTI and measles as compared to previous studies. ${ }^{1-6,9,10}$ This may be explained by the improvement in immunization coverage against the target diseases covered by the expanded programme on immunization and the current breastfeeding practices being advocated.

The overall mortality rate of $4.1 \%$ reported here is in agreement with the $4.0 \%$ reported in Ilesha ${ }^{9}$ but higher than the $2.5 \%$ reported in Lagos. ${ }^{6}$ However, it is lower than figures obtained at the teaching hospitals in Ibadan $^{2}$ and Ilorin. ${ }^{3}$ This may be explained by the fact that critically ill children are referred to these teaching hospitals from both private and public health facilities late in the disease process, after delays and unsuccessful treatments. In consonance with reports from Lagos, ${ }^{6}$ Ibadan, ${ }^{2}$ Ilorin, ${ }^{3}$ and Port Harcourt, ${ }^{4}$ majority of the deaths in this series occurred among underfives, thus indicating their vulnerability and the need to pay special attention to this group of children if an overall reduction in child mortality rate is to be achieved.

In this study, female child mortality rate was 1.5 times higher than male child mortality. Reports from Burkina Faso, ${ }^{21}$ United States of America (Blacks) ${ }^{22}$ and India ${ }^{23-25}$ confirm this trend. The reason for this gender differential in child mortality is not clear. However, in the reports from India, reasons adduced include preference for sons and health care seeking practices. For example, the report indicated that girls are often brought to health facilities in more advance stages of illness than boys, are taken to less qualified doctors when they are ill, and less money is spent on medicines for them than for the boys. ${ }^{25-27}$ However, studies are required to determine whether the same reasons of gender differences are applicable in Nigeria.
Indeed, despite the fact that more males than females were hospitalised, mortality rate was higher among females in this series. This implies that intervention programmes aimed at reducing child mortality would need to correct the bias against girls if equitable access to health care is to be achieved. In consonance with previous reports ${ }^{1-6,9,10}$ preventable diseases such as anaemia, gastroenteritis, measles and ALRTI are other important causes of death in this series. Fortunately, the core programme of integrated management of childhood illnesses (IMCI) strategy is planned to address the five most important causes of childhood death in the developing world. The five target diseases include respiratory infections, diarrhoea, measles, malaria and malnutrition (anaemia may be nutritional), all of which were found to be important causes of childhood deaths in this series.

Other child health interventions such as the immunization programme, oral re-hydration therapy and the baby-friendly hospital initiative are all steps in the right direction. With sincerity and commitment in their implementation by government as well as by health care planners and managers, childhood mortality rate will be substantially reduced in Nigeria.

The commonest causes of death among infants (excluding neonates) and children aged 1-4 years were gastroenteritis and malariainduced anaemia respectively. The implication is that any health intervention to reduce underfive mortality rate must address the prevention and control of this two disease entities. It should be noted that although hospital admission data are inevitably referral and access biased, they can provide useful information on morbidity and mortality in the community.

\section{ACKNOWLEDGEMENTS}

I am grateful to the record officers of SPCH for their assistance in retrieving the relevant case notes. I thank Miss Doris Osarobo for typing the manuscript. 


\section{References}

1. Diakparome MA and Obi JO. The pattern of paediatric emergency at the University of Benin Teaching Hospital. Nig J Paediatr 1980; 7: 43-45.

2. Adeyokunnu AA, Taiwo $\mathrm{O}$ and Antia AU. Childhood mortality among 22255 consecutive admissions in the University College of Hospital, Ibadan. Nig J Paediatr 1980; 7: 7-15.

3. Fagbule D and Joiner KT. Pattern of childhood mortality at the University of Ilorin Teaching Hospital. Nig J Paediatr 1987; 14: $1-5$.

4. Orumabo RS. Analysis of paediatric medical cases admitted into the University of Port Harcourt Teaching Hospital, Nigeria. East Afr Med J 1987; 64: 520-526.

5. Uzodike VO. Paediatric emergencies in general practice. Nig J Paediatr 1976; 3(2): 39-44.

6. Lawal OM and Temiye EO. Pattern of preschool children's admission and mortality in a private health facility in Lagos, Nigeria. Nig Med Pract 1998; 35(3/4): 42-46.

7. Emielu SA (Ed). Senior Secondary Geography. Ilorin: Geographical Bureau Nigeria Ltd, 2000; 170-172.

8. Ojo SO, Ologe KO and Ezechukwu FC (Eds.). Countdown to Senior Certificate Examination in Geography. Ibadan: Evans Brothers Nigeria Ltd, 2000; 228-247.

9. Oyedeji GA. A comparative study of postneonatal childhood admissions in Nigeria and Saudi-Arabia. Nig Med Pract 1996; 32: $1-74$.

10. Ransome-Kuti O. The problems of paediatrics emergencies in Nigeria. Nig Med J 1972; 2: 62-70.

11. Gotze D and da Silva WD. Immunity. In: Bier OG, da Silva WD, Gotze D and Motal I (Eds.). Fundamentals of Immunology. Second edition. New York: Springer-Verlag, 1986; 317-358.

12. Ogbeide MI. Socio-economic factors in diseases of infancy and childhood (with particular reference to Nigeria). Ghana Med $J$ 1968; 7: 129-138.
13. Feacham RG. Interventions for the control of diarrhoeal diseases among young children: promotion of personal and domestic hygiene. Bull Wld Hlth Org 1984 ; 62: 467-476.

14. Rajmil I, Fernamdaz E and Salas T. Gender differences in children hospitalization in Catalonia. Another inequality? Acta Paed Scand 1999; 88: 990-997.

15. Brewster DR and Greenwood BM. Seasonal variation in paediatric diseases in the Gambia, West Africa. Ann Trop Paediatr 1993; 13: 133-146.

16. Hodges $\mathbf{M}$ and Williams RA. Registered infant and under-five deaths in Freetown, Sierra Leone from 1987 to 1991 and comparison with 1969-1979. West Afr J Med 1998; 92: 95-98.

17. Muhe L, Byass P, Freij L, Sandstrom A and Wall S. A one-year community study of under-fives in rural Ethiopia: patterns of morbidity and public health risk factors. Public Health 1995; 109: 99-109.

18. Menge I, Esamai F, Van Reken D and Anabwani G. Paediatric morbidity and mortality at the Eldoret District Hospital, Kenya. East Afr Med J 1995; 72: 165-169.

19. Trape JF. The public health impact of chloroquine resistance in Africa. Amer $J$ Trop Med Hyg 2001; 64 (suppl): 12-17.

20. Whitty CJM, Allan R, Wiseman V, Ochola S, Nakyanzi-Mugisha MV, Vonhm B, Mwita M, Miaka C, Oloo A, Premji Z, Burgess C and Mutabingwa TK. Averting a malaria disaster in Africa - where does the bulk stop? Bull Wld Hlth Org 2004; 82 (5): 381-384.

21. The world fact Book 2002. URL:http:// www.worldfactsnow.com/factbook/country/ Burkinafasol

22. Centers for Disease Control. National Vital Statistics Report 2001; 49: 41. URL:http:// www.cdc.gov/nchs/fastats/pd/f/nvst 490 $\underline{i t 13 . p d f}$

23. Kurz KM and Johnson-Welch C. Gender Bias in Health Care among Children 0-5 Years: Opportunities for Child Survival Programs. Arlington: United States Agency for International Development, the BASICS Projects, 1997. 
58 Journal of Medicine and Biomedical Research

24. Claeson M, Bos ER, Mawji $T$ and Pathmanathan I. Reducing child mortality in India in the new millennium. Bull Wld Hlth Org 2000; 78: 1192-1199.

25. Ganatra B and Hirve S. Male bias in health care utilization for under-fives in rural community in Western India. Bull Wld Hlth Org 1994; 72(1): 101-104.
26. Das Gupta M. Selective discrimination against female children in rural Punjab, India. Pop Dev Rev 1987; 13(1): 77-100.

27. Chatterjie M. A Report on Indian Women from Birth to Twenty. New Delhi: National Institute of Public Co-operation and Child Development, 1990. 